\title{
Temporal trends and anaemia-associated factors in 6- to 59-month-old children in Northeast Brazil
}

\author{
Luciana Pedrosa Leal ${ }^{1,2, *}$, Malaquias Batista Filho ${ }^{1,3}$, Pedro Israel Cabral de Lira', \\ José Natal Figueiroa ${ }^{3}$ and Mônica Maria Osório ${ }^{1}$ \\ ${ }^{1}$ Graduate Program in Nutrition, Federal University of Pernambuco, Recife, Pernambuco, Brazil: ${ }^{2}$ Graduate \\ Program in Nursing, Federal University of Pernambuco, Av. Prof. Moraes Rego s/n', CEP: 50670-901, \\ Cidade Universitária, Recife, Pernambuco, Brazil: ${ }^{3}$ Graduate Program in Maternal and Child Health, Institute \\ of Integrative Medicine 'Professor Fernando Figueira', Recife, Pernambuco, Brazil
}

Submitted 25 June 2011: Accepted 20 January 2012: First published online 14 March 2012

\begin{abstract}
Objective: To analyse the trends and factors associated with anaemia in 6- to 59-month-old children in Northeast Brazil.

Design: Cross-sectional study assessed information from the second and third Pernambuco State Health and Nutrition Surveys carried out in 1997 and 2006. A multiple regression analysis was performed from a conceptual model addressing biological and socio-economic factors, housing and sanitation conditions, maternal factors, health care and nutrition, consumption, morbidity and nutritional status. Poisson's regression with robust variance was used.

Setting: Pernambuco, Brazil.

Subjects: A total of 777 and 993 children, respectively, in the second and third Pernambuco State Health and Nutrition Surveys.

Results: The prevalence of anaemia $(\mathrm{Hb}<11 \mathrm{~g} / \mathrm{dl})$ decreased by $19 \cdot 3 \%(40 \cdot 9 \%$ down to $33.0 \%$ ) between surveys. Maternal education level (less than 8 years in school), households ranked in the lowest environmental index tertile and children between 6 and 23 months of age were the variables common to the final models in the surveys of 1997 and 2006. Elements like living in rural areas, household income less than two minimum official wages and low birth weight were still present in the final model of the 1997 survey. Households ranked in the lowest economic index tertile were associated with anaemia in the model of the 2006 survey.

Conclusions: The study results are quite encouraging from the perspective of reducing the prevalence of anaemia. Maternal education level, environmental conditions and child age were determinant factors in both surveys, and economic factors were determinant in 2006
\end{abstract}

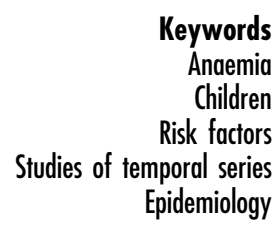

ords

Children

Epidemiology
The high prevalence of anaemia, estimated at $47 \cdot 4 \%$ in children under 5 years of age and $30 \cdot 2 \%$ in women of reproductive age during the period 1993-2005, has not changed worldwide due to the difficulties of coping with and controlling this deficiency ${ }^{(1)}$. In children, anaemia is often associated with low Fe concentration in the diet and with the rapid growth that occurs during the first year of life, also contributing to the insidious consequences that will affect the child's physical and cognitive development and will end up impacting the adult individual's performance at work $^{(1-3)}$.

The control of anaemia in children is linked to multiple cross-interacting and determining factors of biological, health, nutrition, socio-economic and environmental nature that contribute directly or indirectly to its occurrence.

Very few studies make use of representative population samples and therefore can neither evolve in the analysis of anaemia risk determinants nor contribute to the planning of effective measures for their control ${ }^{(4-6)}$. The WHO has recommended that population-based studies be developed to investigate the health and nutritional status of populations and that, among the study objectives, investigation of the prevalence and determinants of anaemia be included as a way of evaluating and supporting new government actions ${ }^{(1)}$.

The health and nutritional status of a population is dynamic and involves matters related to socio-economic development, strategies for improving the health and education conditions of the people and environmental changes. Epidemiological surveys carried out in Brazil have shown a decline in the prevalence of height deficit in children, especially in the 1980 s and 1990 s $^{(7)}$. However, the development of epidemiological surveys conducted at regular time intervals to allow the statistical expression 
of the trends in anaemia is not a reality in all regions of the country. Therefore, it is of utmost importance that the country develops representative population studies to analyse the trends as far as anaemia is concerned, to promote greater understanding of the problem and its associated factors.

The State of Pernambuco, Northeast Brazil, has conducted surveys enabling one to learn about epidemiological trends in the health and nutritional status of the population of children under 5 years of age. Among these surveys, the second State Health and Nutrition Survey (II PESN/PE, 1997) and the third State Health and Nutrition Survey (III PESN/PE, 2006) collected detailed and specific information on anaemia. The present study aimed to analyse the temporal trends and factors associated with anaemia in children aged 6 to 59 months in the State of Pernambuco based in the epidemiological surveys of 1997 and 2006.

\section{Materials and methods}

The State of Pernambuco, Northeast Brazil, has an area of $98146 \mathrm{~km}^{2}$ (37894 square miles) and consists of 185 municipalities, with an estimated population of 8796032 inhabitants in 2010. The population is predominantly urban, concentrating $80 \%$ of the inhabitants.

The data collected for the present study came from two epidemiological surveys, II PESN/PE in 1997 and III PESN/PE in 2006, conducted in partnership with the Department of Nutrition of the Federal University of Pernambuco, as well as the Institute of Integrative Medicine 'Professor Fernando Figueira' and the State of Pernambuco Health Department.

The sampling procedure for both surveys was conducted in three stages. In the first stage, eighteen of the 185 municipalities were selected by means of a systematic drawing process, proportional to the population size of each municipality. In the second stage, out of the previously selected municipalities, forty-five census sectors of II PESN/PE (1997) and thirty-nine census sectors of III PESN/PE (2006) were drawn in a randomly systematic fashion, ensuring the representativeness of the geographical areas of the state. Finally, in each census sector, a point at the end of the parcel facing the east was randomly selected, and from this point the houses where children under 5 years of age lived were identified.

The sample size calculation of II PESN/PE used an error rate of $3 \cdot 4 \%$ and an estimated anaemia prevalence rate of $36 \%{ }^{(2)}$ for the State of Pernambuco, with a $95 \%$ confidence level for the total population of children under 5 years of age in the State. For the purpose of the sample size calculation of III PESN/PE, an anaemia prevalence rate of $40 \%{ }^{(8)}$, an error rate of $3.1 \%$ and a $95 \%$ confidence level were used. In both surveys, an additional $10 \%$ rate was considered to offset any losses, resulting in representative samples of 777 and 993 children, respectively, in II PESN/PE and III PESN/PE.

Data collection was conducted in interviews with mothers or guardians, using forms to record identification details of the household, socio-economic factors, child characteristics, maternal history of pregnancy and childbirth, child history of morbidity, as well as anthropometric records and clinical and laboratory-related records of the children.

The anthropometric assessment consisted of two height w? > and weight measurements performed by different researchers, and the average of these two measurements was recorded in accordance with WHO recommendations ${ }^{(9)}$. These measurements were repeated when the two weight measurements differed by more than $100 \mathrm{~g}$ and the height measurements differed by more than $1 \mathrm{~cm}$. A $150 \mathrm{~kg}$ digital scale with an accuracy of $100 \mathrm{~g}$ was used (model MEA-032000; Plenna, São Paulo, Brazil). The children were weighed barefoot and in minimal clothing, but children under 2 years of age were weighed in the arms of the mother or guardian and their weight was calculated by subtracting the weight of the adult from the total weight.

The height of children under 2 years of age was measured with an infantometer (model Rollametre by Raven; CMS Weighing Equipment Ltd, London, UK) with a total range of $100 \mathrm{~cm}$, graduated in intervals of $0 \cdot 1 \mathrm{~cm}$, with the child in the supine position. For children over 2 years of age, a portable stadiometer (model Stadiometer Alturexata; Alturexata, Belo Horizonte, Brazil) was used. It was made of a removable wooden column with bilateral scale and a usable field going from $35 \mathrm{~cm}$ to $213 \mathrm{~cm}$, graduated in intervals of $0 \cdot 1 \mathrm{~cm}$. The children were measured in the standing position, barefoot, with the upper limbs down along the body and their heels, back and head touching the wooden column.

$\mathrm{Hb}$ was tested in children aged 6 to 59 months with a HemoCue portable $\mathrm{Hb}$ analyser (HemoCue Limited, Sheffield, UK). Anaemia was diagnosed if $\mathrm{Hb}<11 \mathrm{~g} / \mathrm{dl}^{(1)}$.

Socio-economic factors were analysed by considering the following variables: geographical area, income (formal and informal work), literacy level, education and maternal paid work. Housing characteristics and the possession of consumer goods were determined by indices adapted from the study by Oliveira et $a l^{(10)}$. The environmental index was estimated by variables such as: type of housing, possession of housing, type of wall, floor and roof, number of rooms, number of persons in the household, water supply, treatment of drinking water, type of sewage and garbage disposal. Unfavourable situations were assigned a value of 0 and favourable situations were assigned a value of 1 . The sum of these values, categorized into tertiles, characterized the environmental condition of the households. The economic index was established based on the availability of electric power, television set, radio set, refrigerator and stove. The inexistence of consumer goods was assigned a value of 0 , and a value of 1 in the presence of these goods in the 
household. The sum of these values, categorized into tertiles, indicated the availability of goods in the household. Higher tertiles correspond to either more favourable environmental conditions or better availability of goods.

Biological characterization was based on the child's age and gender. Maternal age was analysed as a feature of the mother. Health care, nutrition and infant feeding were analysed according to the following variables: having had prenatal care, number of prenatal visits and duration of breast-feeding. Morbidity was analysed based on the presence of diarrhoea over the previous $15 \mathrm{~d}$. Nutritional status was analysed according to the following variables: birth weight, height/age indicator and weight/age indicator.

Regarding weight and height measurements, reference standard curves were used to assess the nutritional status of the children under 5 years of age ${ }^{(9)}$. The anthropometric assessment was performed using the Anthro software program version 3.01 (2009; WHO, Geneva, Switzerland) according to the following criteria. For the weight/age indicator: $Z$-score $<-2$ indicates low or very low weight; $Z$-score $\geq-2$ indicates appropriate or eutrophic weight; and for the height/age indicator: $Z$-score $<-2$ indicates low height; $Z$-score $\geq-2$ indicates appropriate height.

A bivariate analysis was conducted for each survey, using Poisson's simple regression. The variables statistically associated with anaemia at $P<0 \cdot 20$ were selected to compose the multiple regression models.

A multiple regression analysis was done from a hierarchical conceptual anaemia model based on Osório et al. $^{(3)}$ (Fig. 1). The model consisted of five hierarchical levels to determine anaemia, distributed from the distal block to the proximal block, in the following order: level $1=$ socio-economic factors; level $2=$ housing characteristics and possession of consumer goods; level $3=$ maternal factors; level $4=$ health care and nutrition; level $5=$ nutritional status and morbidity. Some variables associated with anaemia were not used in the models, as they contained similar information.

Poisson's regression with robust variance was used to investigate the influence of the explanatory variables on the prevalence of anaemia ${ }^{(11)}$. The backward method was used. The child's age was entered and maintained in the model as a control variable. The variables of the first hierarchical level were analysed together and the variables with significance $P \geq 0 \cdot 20$ were progressively discarded. Then, the second hierarchical level variables were added to the model and the same procedure was adopted, and the variables at this level with $P \geq 0 \cdot 20$ were progressively discarded. Thus, all hierarchical levels were analysed. At the end of the models for the surveys of 1997 and 2006, variables with $P<0 \cdot 05$ were considered significant. Variables with $P<0 \cdot 20$ were retained in the models at each hierarchical level.

The statistical significance was determined by the Wald test for heterogeneity and linear trend for ordinal variables, including estimates of the adjusted prevalence ratios and respective $95 \%$ confidence intervals.
Regarding the surveys of 1997 and 2006, the following variables joined the regression models: child's age; level $1=$ geographical area, family income, maternal education and maternal paid work; level $2=$ environmental index and economic index; level $3=$ maternal age; level $4=$ number of prenatal visits; level $5=$ diarrhoea and height/age indicator. Birth weight was part of the model in the 1997 survey.

The temporal trend of anaemia in the State of Pernambuco was also analysed according to the distribution of $\mathrm{Hb}$ by geographical area, and according to the child's age in the surveys of 1997 and 2006. In order to check the variation in $\mathrm{Hb}$ concentration between the two surveys, average equality tests (ANOVA) were used.

Data analysis used Epi Info software version 6.04 (Centers for Disease Control and Prevention, Atlanta, GA, USA) and R, version $2 \cdot 10 \cdot 1$ (2009; The R Foundation for Statistical Computing, Vienna, Austria).

The projects of II PESN/PE and III PESN/PE were approved by the Committee of Ethics in Human Research, according to resolution 196/96 of the National Health Council (Brazilian Ministry of Health). Children diagnosed with anaemia received ferrous sulfate for initial treatment and were referred for medical care.

\section{Results}

The III PESN/PE (2006) showed a prevalence of anaemia in children under 5 years of age of $33 \cdot 0(95 \%$ CI $30 \cdot 1,36 \cdot 1) \%$ in the State, and 31.5 (95\% CI 28.2, 35.1) \% and 37.0 (95\% CI $31 \cdot 3,43 \cdot 0) \%$ in the urban and rural areas, respectively. In this survey, there was no statistically significant difference in the prevalence of anaemia according to geographical area $(P>0.05)$. In the II PESN/PE (1997), these prevalences were $40 \cdot 9$ (95\% CI $37 \cdot 4,44 \cdot 5) \%$ in the State, and $37 \cdot 8(95 \%$ CI $33 \cdot 6,42 \cdot 1) \%$ and $51 \cdot 4(95 \%$ CI $45 \cdot 0,57 \cdot 7) \%$ in the urban and rural areas, respectively; with a significant difference between these areas $\left(P<0 \cdot 001^{(8)}\right.$; Fig. 2$)$.

The average $\mathrm{Hb}$ concentration in Pernambuco in the surveys of 1997 and 2006 was $10 \cdot 9$ (sD 1.6) g/dl and 11.4 (sD $1 \cdot 3) \mathrm{g} / \mathrm{dl}$, respectively; an increase was observed in the average $\mathrm{Hb}$ concentration of $0.5 \mathrm{~g} / \mathrm{dl}$ between the two surveys. In the $\mathrm{Hb}$ concentration distribution by geographical area, there was a left-shifting tendency in the curve of 1997. The Hb concentration averages in urban areas were 11.1 (SD 1.5) g/dl and 11.5 (SD 1.3) g/dl in 1997 and 2006, respectively, and in rural areas they were 10.6 (SD 1.6) $\mathrm{g} / \mathrm{dl}$ in 1997 and 11.2 (SD 1.3) $\mathrm{g} / \mathrm{dl}$ in 2006. The greatest increase in $\mathrm{Hb}$ concentration occurred in the rural areas $(0.6 \mathrm{~g} / \mathrm{dl})$. In both surveys, Hb concentration averages between urban and between rural areas were statistically significant $(P<0 \cdot 001 ;$ Fig. 3$)$.

In the same period, $\mathrm{Hb}$ concentration averages increased by $0 \cdot 4 \mathrm{~g} / \mathrm{dl}$ and $0 \cdot 3 \mathrm{~g} / \mathrm{dl}$ in the age ranges 6 to 23 months and 24 to 59 months, respectively. The $\mathrm{Hb}$ concentration 


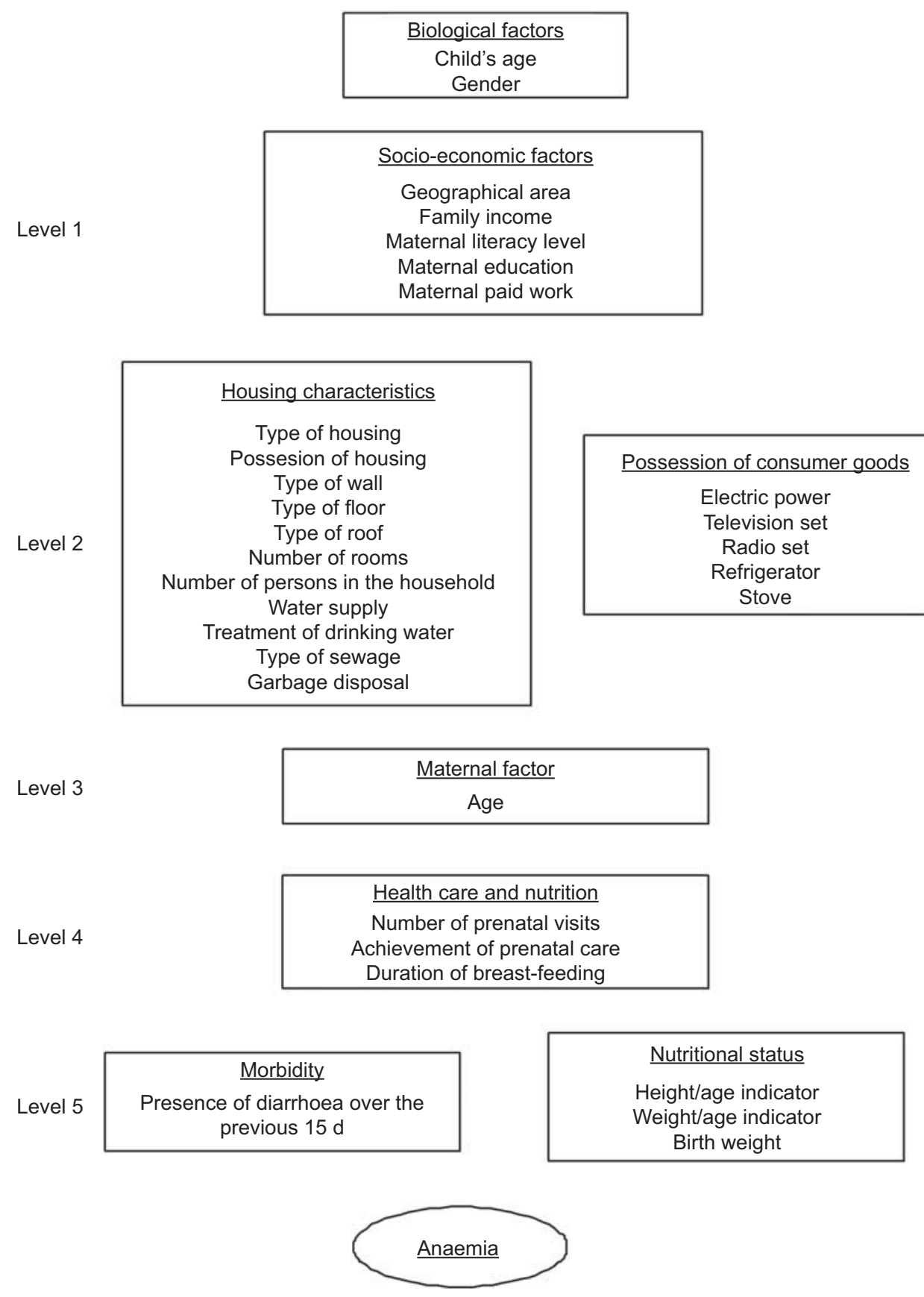

Fig. 1 Hierarchical conceptual anaemia model used in the present analysis

curves in relation to the child's age showed a positive trend in both groups during the surveys of 1997 and 2006, but more so in the 6 to 23 months age range (Fig. 4). The curves by age at 2 years showed statistically different $\mathrm{Hb}$ concentration averages $(P<0 \cdot 001)$. In the children aged 6 to 23 months, Hb averages were $10 \cdot 4$ (SD $1 \cdot 5) \mathrm{g} / \mathrm{dl}$ in 1997 and $10 \cdot 8(\mathrm{sD} 1 \cdot 2) \mathrm{g} / \mathrm{dl}$ in 2006. Children aged 24 to 59 months showed $\mathrm{Hb}$ averages of 11.5 (SD 1.4 ) g/dl and (sD $1 \cdot 2$ ) $11 \cdot 8 \mathrm{~g} / \mathrm{dl}$ in 1997 and 2006, respectively.
The variables that remained significant in the final multiple regression model in the 1997 survey were: child's age; level 1 =geographical area of residence, family income and maternal education; level $2=$ environmental index; and level $5=$ weight birth, adjusted by economic index and age of the mother. In the 2006 survey, the variables that showed statistical significance in the final multiple regression model were: child's age; level $1=$ maternal education; level 2 =environmental index and economic 


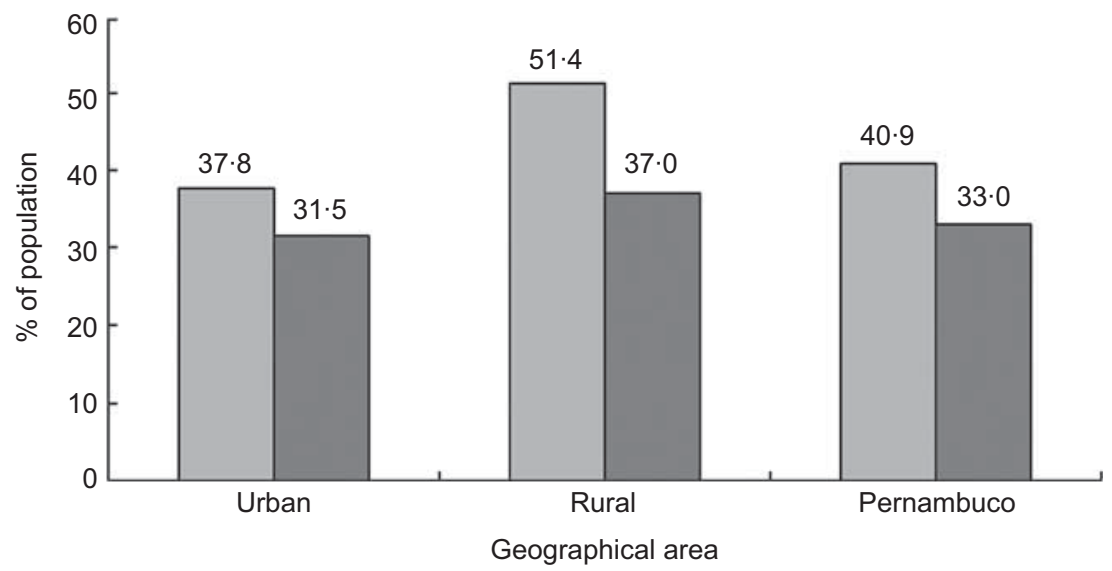

Fig. 2 Prevalence of anaemia in 6- to 59-month-old children by geographical area, State of Pernambuco, Northeast Brazil, 1997 ( $\square$ ) and 2006 ( $\square$ ). Data are from the second and third Pernambuco State Health and Nutrition Surveys carried out in 1997 and 2006, respectively; anaemia prevalence in 1997 sourced from Osório et al. $(2001)^{(8)}$
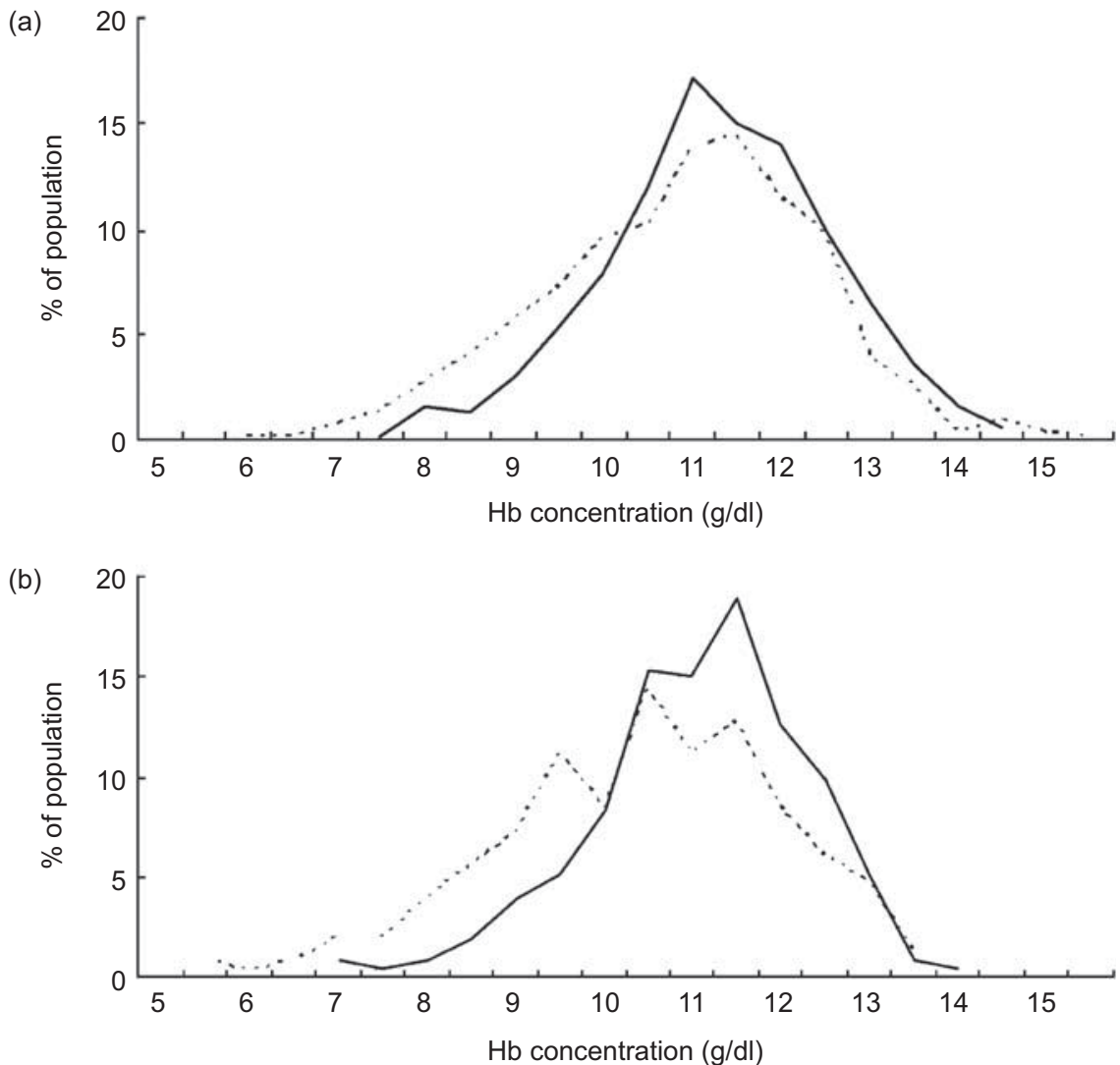

Fig. $3 \mathrm{Hb}$ concentration distribution in 6- to 59-month-old children by geographical area, (a) urban and (b) rural, State of Pernambuco, Northeast Brazil, 1997 (- - - ) and 2006 ( ). Data are from the second and third Pernambuco State Health and Nutrition Surveys carried out in 1997 and 2006, respectively

index, adjusted by maternal paid work, mother's age and height/age indicator (Table 1).

\section{Discussion}

The prevalence of anaemia among children under 5 years of age in the State of Pernambuco in the surveys of 1997 and 2006 decreased by $19 \cdot 3 \%(40 \cdot 9 \%$ to $33 \cdot 0 \%)$. The most significant reduction occurred in rural areas $(51 \cdot 4 \%$ to $37 \cdot 0 \%$ ), representing a decline of $28 \cdot 8 \%$. The urban areas had a reduction of $16 \cdot 7 \%(37 \cdot 8 \%$ to $31 \cdot 5 \%)$. Although a significant reduction was observed, the current prevalence rates are similar to those estimated by WHO for various regions of the world, ranging from $21.7 \%$ in Europe 

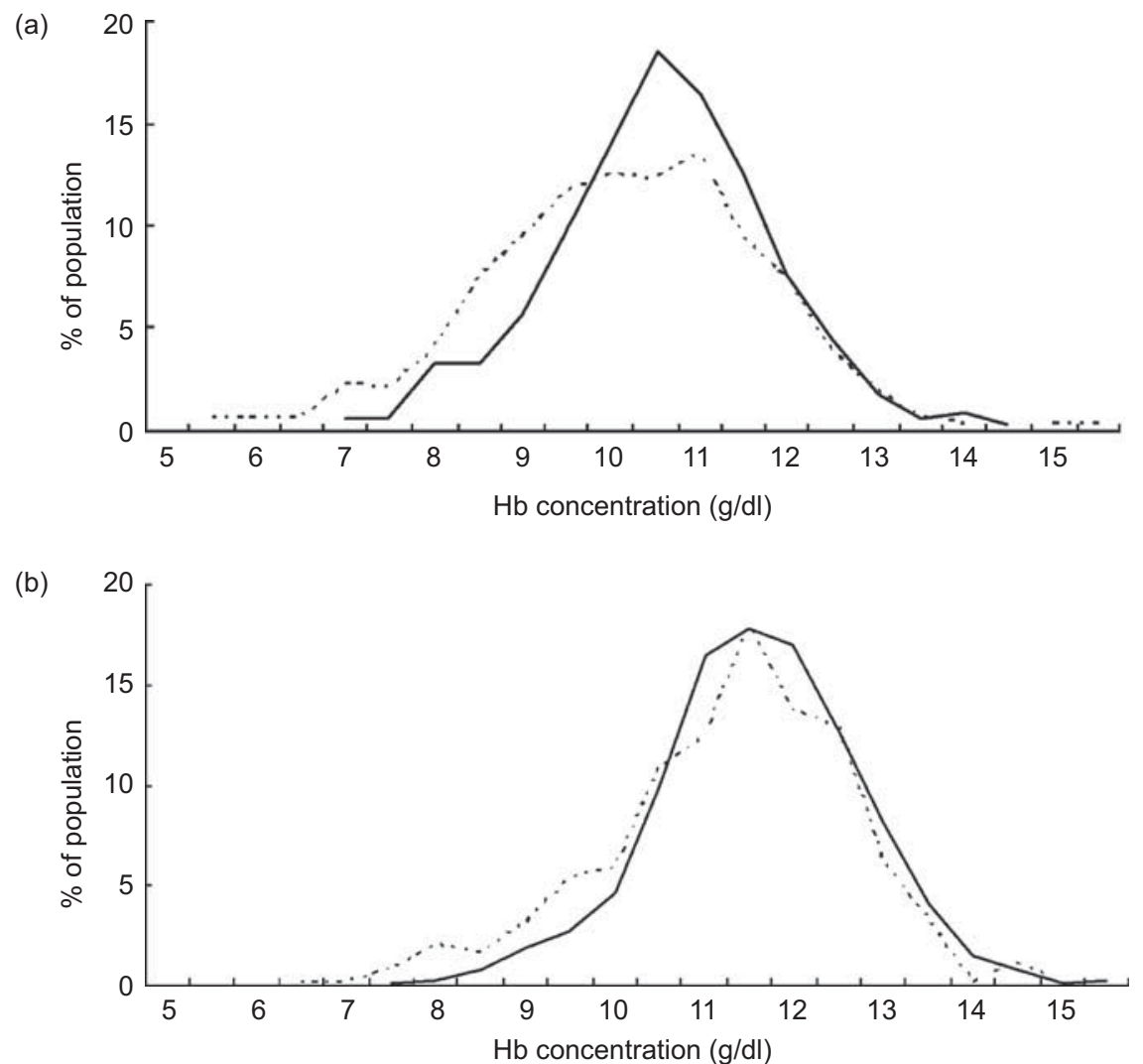

Fig. $4 \mathrm{Hb}$ concentration distribution by age range, (a) 6 to 23 months and (b) 24 to 59 months, State of Pernambuco, Northeast Brazil, 1997 (- - -) and 2006 (- $(-$. Data are from the second and third Pernambuco State Health and Nutrition Surveys carried out in 1997 and 2006, respectively

Table 1 Adjusted prevalence ratios of anaemia in 6- to 59-month-old children, State of Pernambuco, Northeast Brazil, 1997 and 2006 . Data are from the second and third Pernambuco State Health and Nutrition Surveys carried out in 1997 and 2006, respectively

\begin{tabular}{|c|c|c|c|c|c|c|c|}
\hline \multirow[b]{2}{*}{ Level } & \multirow[b]{2}{*}{ Variable } & \multicolumn{3}{|c|}{$1997^{*}$} & \multicolumn{3}{|c|}{$2006+$} \\
\hline & & PR & $95 \% \mathrm{Cl}$ & $P$ & PR & $95 \% \mathrm{Cl}$ & $P$ \\
\hline \multirow{11}{*}{ Level 1} & Age (months) & & & & & & \\
\hline & $\begin{array}{l}\geq 24 \\
6-24\end{array}$ & $\begin{array}{l}1 \cdot 00 \\
2 \cdot 01\end{array}$ & $\begin{array}{c}\text { Ref. } \\
1 \cdot 70,2 \cdot 36\end{array}$ & $<0.001$ & $\begin{array}{l}1 \cdot 00 \\
2 \cdot 66\end{array}$ & $\begin{array}{c}\text { Ref. } \\
2 \cdot 23,3 \cdot 19\end{array}$ & $<0.001$ \\
\hline & Area & & & & & & \\
\hline & Urban & $1 \cdot 00$ & Ref. & 0.023 & & & \\
\hline & Rural & $1 \cdot 19$ & $1 \cdot 02,1 \cdot 37$ & & & & \\
\hline & Family income (minimum salaries) & & & & & & \\
\hline & $\geq 2$ & 1.00 & Ref. & 0.023 & & & \\
\hline & $<2$ & $1 \cdot 19$ & $1 \cdot 02,1 \cdot 38$ & & & & \\
\hline & Maternal education (years) & & & & & & \\
\hline & $\geq 9$ & 1.00 & Ref. & 0.044 & 1.00 & Ref. & 0.016 \\
\hline & $0-8$ & $1 \cdot 29$ & $1 \cdot 01,1 \cdot 66$ & & $1 \cdot 30$ & $1 \cdot 05,1.61$ & \\
\hline \multirow[t]{8}{*}{ Level 2} & Environmental index (tertile) & & & & & & \\
\hline & 3 & $1 \cdot 00$ & Ref. & $<0.001$ & $1 \cdot 00$ & Ref. & 0.005 \\
\hline & 2 & $1 \cdot 01$ & $0 \cdot 81,1 \cdot 26$ & & $1 \cdot 46$ & $1 \cdot 12,1 \cdot 89$ & \\
\hline & 1 & 1.49 & $1 \cdot 17,1 \cdot 89$ & & 1.51 & $1 \cdot 15,1.98$ & \\
\hline & Economic index (tertile) & & & & & & \\
\hline & 3 & & & & $1 \cdot 00$ & Ref. & 0.022 \\
\hline & 2 & & & & 1.03 & $0.84,1.27$ & \\
\hline & 1 & & & & $1 \cdot 36$ & $1.09,1.69$ & \\
\hline \multirow{3}{*}{ Level 5} & Birth weight (g) & & & & & & \\
\hline & $\geq 2500$ & 1.00 & Ref. & 0.037 & & & \\
\hline & $<2500$ & $1 \cdot 28$ & $1 \cdot 01,1 \cdot 61$ & & & & \\
\hline
\end{tabular}

PR, prevalence ratio; Ref., referent category.

*Adjusted by economic index and age of the mother.

†Adjusted by maternal paid work, mother's age and height/age indicator. 
to $67 \cdot 6 \%$ in Africa, over the period $1993-2005$, showing that anaemia is a problem of global nature ${ }^{(1)}$.

In addition to the survey in Pernambuco, other studies conducted in Brazil ${ }^{(2,12)}$ have shown prevalence rates of anaemia above the $29 \cdot 3 \%$ value estimated by WHO for the Americas ${ }^{(1)}$. Prevalence rates above $40 \%$ in the country, mainly in children under 2 years of age in rural areas $^{(2,8)}$, match what WHO states regarding Brazil being among the countries where anaemia is deemed a serious public health problem ${ }^{(1)}$.

In other Brazilian states, specifically in the city of São Paulo and in the State of Paraiba, prevalence rates of anaemia in children grew substantially, with marked growth in the 1990s compared with the previous decade: $31.7 \%$ and $88.5 \%$, respectively ${ }^{(2,13)}$. However, the present study demonstrated a decreasing trend of this problem in the State of Pernambuco.

In the geographical areas in 2006, the prevalence of anaemia showed a similar trend to that of the State; unlike the scenario in 1997, in which the rural areas had significantly higher prevalence rates than the inner city and the metropolitan area of Recife ${ }^{(8)}$. Such a similarity in prevalence rates is explained by the remarkable decline in anaemia in the rural areas, thus representing a significant reduction when compared with the urban areas ${ }^{(8)}$. This reality leads to a more uniform distribution of anaemia among the rural and urban areas of the State, as shown by the loss of significance of geographical area in the regression model of the 2006 survey.

Despite the observed increase in average $\mathrm{Hb}$ concentrations between the surveys in 1997 and 2006, age remained as one of the main explanatory variables, reinforcing its relevance in the occurrence of anaemia and corroborating the results of other studies ${ }^{(5,12)}$.

Lower $\mathrm{Hb}$ averages in children under 24 months of age are related to the physiological characteristics of rapid growth and the consequent need for increased Fe intake. The influence of other determinants has also been described, such as the type of cow's milk and derived products-based diet offered to the child ${ }^{(14,15)}$.

In the process of multiple regression analysis, among the factors included in the most distal level of the anaemia hierarchical conceptual model, maternal education was still present in the final regression models in the surveys of 1997 and 2006. The association between higher maternal education and lower prevalence of anaemia is related to the realization that maternal education enables mothers' empowerment regarding health information and care for their children ${ }^{(5,16)}$.

Between the 1997 and 2006 surveys, there was an increase in the percentage of families with income less than two minimum official wages ( $44.5 \%$ in $1997,69 \cdot 8 \%$ in 2006) even though that threshold increased from about \$US 222 in 1997 to \$US 318 in 2006. It was found that low family income represented a risk for anaemia in the 1997 survey, which was not shown in 2006. This result explains the failure of using family income as separate information to determine socio-economic conditions ${ }^{(6,17)}$, due to the fact that most families have some kind of informal income, coming from either informal activities or social benefits provided by the government.

Thus, consumer goods - intermediate-level factors in the model that determines anaemia - seem to better explain families' economic situation as part of a context of quality of life that translates into higher socio-economic level. This behaviour expresses the change in the determinants of anaemia among children in the State of Pernambuco over the past decade, in which income an explanatory factor for anaemia in 1997 - is replaced by the economic index in 2006 .

Also in relation to the intermediate levels for determining anaemia, as far as housing and sanitation conditions are concerned, the situation in the State remained the same, with the environmental index being significant in the regression models of the surveys of 1997 and 2006. The contribution of housing and sanitation conditions in determining anaemia is an expected factor in places where poor conditions are found, further predisposing children to infectious and parasitic diseases that, on their own, also contribute to the presence of nutritional deficiencies ${ }^{(1)}$.

At the proximal level of the conceptual model, low birth weight was significantly associated with anaemia in the final model of the 1997 survey. The prevalence of low birth weight was $8.3 \%$ in 1997 and $8.6 \%$ in 2006. Low birth weight predisposes to a reduction in the Fe reserves of newborns and the subsequent need for early supplementation, concomitant with a diet richer in this mineral ${ }^{(18,19)}$. In the 2006 survey, birth weight lost its significance in the final model.

As per the explanatory models for the surveys of 1997 and 2006, out of the variables that remained in the final regression models, only three were similar: child's age, maternal education and environmental index.

Measures adopted by the Ministry of Health since 2002, such as the fortification of wheat flour and maize, and the National Iron Supplementation Program from 2005 may have contributed to the reduction in the prevalence of anaemia in the 2006 survey. Considering that the present study is the first population-based one to show a declining trend of anaemia in Brazil, more temporal trend studies will be necessary to provide broader discussions on this subject.

The study results are quite encouraging from the perspective of reducing the prevalence of anaemia in children under 5 years of age, something that has not been found in the Brazilian states in the past decade ${ }^{(2,13)}$. However, this situation should be seen with caution by governments, given that the prevalence of anaemia is still a serious public health problem in the State of Pernambuco.

The importance of maintaining government programmes to prevent anaemia, as implemented by the Brazilian Ministry of Health earlier during this decade, can never be emphasized too much. However, the set of 
determinants points to a scenario in which broader measures - ones that may ensure access to education, employment, basic sanitation, safe water to drink, consumer goods, improvement in living conditions, availability of health services and access to good quality and safe food should also be among the government's priority actions.

\section{Acknowledgements}

This work was supported by Conselho Nacional de Desenvolvimento Científico e Tecnológico, Brazil. There are no conflicts of interest. L.P.L., M.B.F., P.I.C.d.L. and M.M.O. wrote the manuscript and designed the study. L.P.L., J.N.F. and M.M.O. conducted the analyses. The authors thank the mothers and children who participated in this research, and the field staff for their support.

\section{References}

1. World Health Organization (2008) Worldwide Prevalence of Anaemia 1993-2005: WHO Global Database on Anaemia. Geneva: WHO.

2. Monteiro CA, Szarfarc SC \& Mondini L (2000) (Secular trends in child anemia in São Paulo city, Brazil (1984-1996)). Rev Saude Publica 34, Suppl. 6, S62-S72.

3. Osório MM, Lira PIC \& Ashworth A (2004) Factors associated with $\mathrm{Hb}$ concentration in children aged 6-59 months in the State of Pernambuco, Brazil. Br J Nutr 91, 307-314.

4. Custodio E, Descalzo MA, Roche J et al. (2008) Nutritional status and its correlates in Equatorial Guinean preschool children: results from a nationally representative survey. Food Nutr Bull 29, 49-58.

5. Kikafunda JK, Lukwago FB \& Turyashemererwa F (2009) Anaemia and associated factors among under-fives and their mothers in Bushenyi district, Western Uganda. Public Health Nutr 12, 2302-2308.

6. Agho KE, Dibley MJ, D'Este C et al. (2008) Factors associated with haemoglobin concentration among TimorLeste children aged 6-59 months. J Health Popul Nutr 26, 200-209.
7. Batista Filho M, Souza AI, Miglioli TC et al. (2008) (Anemia and obesity: a paradox of the nutritional transition in Brazil). Cad Saude Pablica 24, Suppl. 2, S247-S257.

8. Osório MM, Lira PIC, Batista Filho M et al. (2001) Prevalence of anemia in children 6-59 months old in the State of Pernambuco, Brazil. Pan Am J Public Health 10, 101-107.

9. World Health Organization (2006) WHO Child Growth Standards: Length/Height-for-Age, Weight-for-Age, Weightfor-Length, Weight-for-Height and Body Mass Indexfor-Age. Methods and Development. Geneva: WHO.

10. Oliveira LPM, Barreto ML, Assis AMO et al. (2007) (Determinants of linear growth retardation in Brazilian preschool children: a multilevel approach). Cad Saude Publica 23, 601-613.

11. Barros AJD \& Hirakata VN (2003) Alternatives for logistic regression in cross-sectional studies: an empirical comparison of models that directly estimate the prevalence ratio. BMC Med Res Methodol 3, 21.

12. Konstantyner T, Taddei JAAC, Oliveira MN et al. (2009) Isolated and combined risks for anemia in children attending the nurseries of daycare centers. J Pediatr 85, 209-216.

13. Oliveira RS, Diniz AS, Benigna MJC et al. (2002) (Magnitude, geographic distribution and trends of anemia in preschoolers, Brazil). Rev Saude Publica 36, 26-32.

14. Oliveira MAA, Osório MM \& Raposo MCF (2007) Socioeconomic and dietary risk factors for anemia in children aged 6 to 59 months. J Pediatr 83, 39-46.

15. Hadler MC, Colugnati FA \& Sigulem DM (2004) Risks of anemia in infants according to dietary iron density and weight gain rate. Prev Med 39, 713-721.

16. Tympa-Psirropoulou E, Vagenas C, Dafni O et al. (2008) Environmental risk factors for iron deficiency anemia in children 12-24 months old in the area of Thessalia in Greece. Hippokratia 12, 240-250.

17. Ngnie-Teta I, Receveur O \& Kuate-Defo B (2007) Risk factors for moderate to severe anemia among children in Benin and Mali: insights from a multilevel analysis. Food Nutr Bull 28, 76-89.

18. Vendt N, Grunberg H, Leedo S et al. (2007) Prevalence and causes of iron deficiency anemias in infants aged 9 to 12 months in Estonia. Medicina (Kaunas) 43, 947-952.

19. Mamiro PS, Kolsteren P, Roberfroid D et al. (2005) Feeding practices and factors contributing to wasting, stunting and iron deficiency anaemia among 3-23 month old children in Kilosa District, Rural Tanzania. J Health Popul Nutr 23, 222-230 